\title{
A Banach algebra which is generated by idempotents
}

\section{A. ZIVARI-KAZEMPOUR}

\section{ABSTRACT.}

In this paper we show that the Banach algebra $C_{0}(X)$, where $X$ is a locally compact Hausdorff space, is generated by idempotents if and only if $X$ is totally disconnected.

Acknowledgements. The useful comments of the anonymous referees are gratefully acknowledged.

\section{REFERENCES}

[1] Bart, H., Ehrhardt, T. and Silbermann, B., Logarithmic residues in the Banach algebra generated by the compact operators and the identity, Math. Nachr., 268 (2004), 3-30

[2] Bottcher, A. and Spitkovsky, I. M., Classification of the finite-dimensional algebras generated by two tightly coupled idempotents, Linear Algebra Appl., 439 (2013), 538-551

[3] Bottcher, A. and Spitkovsky, I. M., Group inversion in certain finite-dimensional algebras generated by two idempotents , Indag. Math. (N.S), 23 (2012), 715-732

[4] Bottcher, A. and Spitkovsky, I. M., On certain finite-dimensional algebras generated by two idempotents, Linear Algebra Appl., 435 (2011), 18231836

[5] Finck, T., Roch, S. and Silbermann, B., Banach algebras generated by two idempotents and one flip, Math. Nachr., 216 (2000), 73-94

[6] Folland, G. B., Real Analysis: modern techniques and their application, Second edition, New York, 1999

[7] Ilie, M. and Spronk, N., The algebra generated by idempotents in a Fourier-Stieltjes algebra, Houston J. Math., 33 (2007), No. 4, 1131-1145

[8] Krupnik, N., Symmetrization of the symbol in Banach algebras generated by idempotents, Integral Eq. Operator Theory., 31 (1998), $470-481$

[9] Krupnik, N., Roch, S. and Silbermann, B., On C*-algebras generated by idempotents, J. Func. Anal., 137 (1996), 303-319

[10] Krupnik, N. and Spigel, E., Invertibility symbol for a Banach algebra generated by two idempotents and a shift, Integral Eq. Operator Theory., 17 (1993), 567-578

[11] Munkers, J. R., Topology, Second edition, Upper Saddle River: Prentice Hall, 2000

[12] Rudin, W., Real and Complex Analysis, New York, 1970

DEPARTMENT OF MATHEMATICS

AYATOLLAH BORUJERDI UNIVERSITY

BORUJERD, IRAN.

E-mail address: zivarieabru.ac.ir 